Fu-qiang Wang, Jun Liu

\title{
The Supply Chain Contract Design under Cap-and-Trade Mechanism with Free Riding
}

\begin{abstract}
This paper studies the influence of free riding on enterprise product pricing and carbon emissions reduction investment, as well as the contract design to achieve supply chain coordination under the carbon trading mechanism. First, we discuss the situation where carbon emissions reduction investment affects the product price and income. It demonstrates that the optimal investment of the upstream manufacturer increases with the degree of the free riding of the downstream manufacturer. The upstream manufacturer can improve their carbon reduction investment and the whole supply chain achieves Pareto improvement when the investment cost sharing contract is introduced. Nevertheless, under the cost-sharing contract the optimal investment of the decentralized supply chain is still lower than that of the centralized supply chain, and only in some particular cases can the two types of supply chain achieve equal total profits. Then, we preliminarily explore the situation where the product price and income is influenced by carbon emissions reduction investment. The consequences indicate that the optimal investment of the upstream manufacturers in this situation is less than the former one's, and the transfer payment mechanism is able to improve the level of the supply chain overall carbon emissions-reduction. Moreover, compared to the former situation, the effects of free riding of the downstream manufacturer are even more serious. The conclusions can provide some intellectual support for manufacturing enterprises to make reasonable emissions reduction strategies and coordinate the supply chain existing in free riding.
\end{abstract}

Keywords: carbon emissions reduction, free riding, supply chain contract design, cap-and-trade

Manuscript received June 19, 2015; accepted September 21, 2015

Fu-qiang Wang ( $\bowtie)$, Jun Liu

Collaborative Innovation Center of Resource-conserving \& Environment-friendly Society and Ecological Civilization, School of Business, Central South University, Changsha 410083, China

Email:wfqqfw11@gmail.com

\section{Introduction}

At present, the national governments, enterprises and scholars have formed a consensus that the greenhouse effect caused by carbon dioxide and other greenhouse gas emissions is the culprit for global warming and extreme climate, and the carbon emissions generated by humans in economic activities is the most important cause of the greenhouse effect. Carbon emission reduction is imperative.

Enterprises, critical human economic activity, play an important role in the responsibility for climate change in a low carbon environment. In the face of pressure from government policy-makers, customer spending habits, preference behavior change and so on, enterprises make an effort to pursue the economic efficiency and at the same time need to reduce carbon emissions. The emergence of the carbon trading market makes it that quotas for carbon emissions, undifferentiated goods, generated in production, can be traded nationally and internationally, between enterprises, which eliminates geographical boundaries and brings new opportunities to businesses. To obtain new competitive advantages with the background of a low carbon economy, many enterprises gradually consider the optimal operation strategy under carbon regulations and trade, such as Tesco of Britain, Walmart and Dell of the US, Haier of China, which have already achieved preliminary results.

According to the research of Caro, Corbett, Tan, and Zuidwijk (2013), Nayak and Kumar (2006), Koomen (2012), Xie and Zhao (2013) and Wang and Zhao (2014), the enterprises in a supply chain that implement carbon emission reduction can affect their own carbon emissions but can also impact the emissions at upstream or downstream companies. A typical product goes through numerous manufacturing and transportation stages operated by a number of companies in a supply chain. Each firm can invest in reducing emissions in its own operations but can also affect the emissions at upstream or downstream companies by changing a product's dimensions, form, flexibility, strength, required storage conditions, durability, 
etc. Some firms can affect others' emissions by collaboration, coordination, information sharing, or even simply by leveraging their economic power. For example, enterprises in the supply chain may be free riding of others' carbon emissions reduction investment.

Based on the above background, this paper studies the optimal decisions and supply chain coordination problems when the upstream firm, in the face of free riding of the downstream firm, invests in carbon emissions reduction. Due to the free riding, behavior may affect the enthusiasm of upstream enterprise's carbon emissions reduction investment and the whole effect to reduce emissions; it has practical significance to investigate the impact of free riding on enterprise product pricing and carbon emissions reduction investment, as well as the contract design to achieve supply chain coordination under the carbon trading mechanism.

\section{Literature review}

The available literature associated with this article mainly focuses on the enterprises' production operation adjustment and the supply chain coordination under the policy of carbon regulation and the free riding problems' contract coordination in the supply chain, etc.

The representative literatures concentrating on the enterprises' production operation adjustment under the policy of carbon regulation are as follows. Cachon (2014) studied how a retailer's downstream distribution networks in a supply chain to meet carbon emissions constraints as well as minimizes the cost of operation and consumption. Du, Dong, Liang, and Zhang (2009) investigated the effect of emissions permits and carbon cap-and-trade mechanism on emissions dependency enterprise production strategies. Zhang, Nie, and Du (2011) researched the manufacturer's optimal production strategy under the stochastic demand and carbon cap-and-trade mechanism. He and Ma (2011) established the enterprise's production and storage optimization decision model under the control of carbon emissions by using the theory of storage methods. Hua, Cheng, and Wang (2011) systematically studied the enterprise management of their carbon footprint under the carbon cap-and-trade mechanism and analyzed in detail the impact of the carbon cap and carbon price of order quantities and carbon emissions of the enterprise. Benjaafar, Li, and Daskin (2010) investigated the ways of adjusting the operations to reduce carbon emissions and the influence of cooperation to cost and reducing carbon emissions. Xia, Zhao, He, and Li (2014) considered the effect of carbon emissions reduction on demand in the process of production and investigated the game of emission reduction between manufacturers and suppliers when the carbon trade and carbon emissions constraints are integrated into the enterprise profit function. Ma, Song, and Chen (2014) studied the optimal pricing and carbon emissions strategies of a low carbon product of a single enterprise in a carbon trading system based on the quota system.

The representative literature focusing on the supply chain coordination under the policy of carbon regulations are as follows. Du, Ma, Fu, Zhu, and Zhang (2015) studied the possibility of coordination between an emissions dependent manufacturer and an emissions permit supplier in a supply chain under the carbon cap-and-trade mechanism. Chaabane, Ramudhin, and Paquet (2012) studied the design of a sustainable supply chain under the carbon capand-trade mechanism. Shi and Zhao (2013) studied the supply chain coordination with three different situations in a monopoly and a high emissions supplier and an oligarch manufacturers' industry structure. Benjaafar, Li, and Daskin (2013) added carbon emissions constraints to the classic production model and tested the adjustment of the supply chain procurement and production plan under carbon emissions constraints. They indicated that by production adjustment and coordination of supply chain members' carbon emissions fall sharply and on this premise no significant increase in cost can be achieved. Li and Zhao $(2014,2015)$ studied the problem of supply chain coordination under a low carbon background. Xu, Zhao, and Yuan (2015) discussed differential pricing and the coordination mechanism of a supply chain with a low carbon and two ordinary products manufacturers and a retailer of a two-stage supply chain system as their research object.

The representative literature concerning free riding problems' contract coordination in a supply chain are as follows, Carlton and Chevalier (2001) studied the free riding phenomena that consumers accept service from the brick-and-mortar retailers, but purchase products by network channels and the manufacturers' ways of controlling free riding behavior, such as pricing and the restriction of available supply to Internet websites. Xing and Liu (2012) studied sales effort coordination for a supply chain with one manufacturer and two retail channels, where an online retailer offers a lower price and free rides a brick-andmortar retailer's sales effort.Ai, Ma, Chen, and Tang (2011) analyzed the relationship characteristics of decision making behavior for price and service with performance through modeling a traditional retailer channel and a manufacturer's E-channel, resulting in identifying the impacts of competitive pricing and service free-riding on the performance. Furthermore, the three-tariff range for coordination and the influence of price competition and service free-riding on the coordination mechanism are explored, which provides a basic logistical basis for implementation of the coordination mechanism. Ding and Liu (2013) analyzed the optimal prices of dual channels for the entire supply chain and the competing equilibrium of various dual structures through modeling on dual channels, and studied the application of the revenue sharing contracts in various dual channel structures when a free riding problem exists. $\mathrm{Xu}$ and Liu 
(2014) studied the information free-riding behavior of the direct-sale channel on the internet controlled by one manufacturer to the traditional retail channel controlled by one retailer in one dual-channel supply chain (DCSC). One buy-back plus information service subsidy contract is put forward to coordinate this DCSC by using the contract theory. The numerical simulation demonstrates the reasonability of the proposed models and feasibility of the coordinative contracts.

In conclusion, the existing research mainly focuses on the influence of different policies of carbon regulations to enterprises' production operation adjustment, the design of the low carbon supply chain coordination mechanism, the coordination of the free riding problem in the supply chain when traditional channels and electronic channels coexist, etc. Few people have investigated the free riding problem and the coordination of the problem when upstream and downstream enterprises are reducing carbon emissions in the environment of a low carbon economy. The coordination of free riding behavior for enterprises in an investment to reduce emissions can enhance the enterprise's incentive to reduce emissions, but can also be of great significance in improving the mechanism of carbon trading, reducing carbon emissions in the supply chain by making full use of the carbon trading market. Therefore, this paper investigates the impact of free riding on an enterprise's product pricing and carbon emissions reduction investment, as well as the contract design to achieve supply chain coordination under the carbon trading mechanism on the basis of existing research.

\section{Model descriptions}

This paper considers a simple supply chain containing an upstream and a downstream enterprise. Products manufacturing successively goes through two stages including the upstream manufacturer $M_{1}$ and the downstream manufacturer $M_{2}$. The game between upstream and downstream manufacturers is the Stackelberg one, where the upstream manufacturer is the leader and the downstream manufacturer is the follower. Considering the carbon trading market environment and facing the pressure from the government to reduce carbon emissions, enterprises determine the products' price and output and carbon emissions reduction investment. Carbon emissions reducing actions will produce a mutual influence between enterprises. When the upstream enterprise invests to reduce emissions, the downstream enterprise can accordingly reduce its carbon emissions without paying the additional cost and effort. In reality, in order to achieve a certain extent of reduction in carbon emissions, the upstream firm invests in reducing emissions by changing a product's dimensions, form, flexibility, strength, required storage conditions, durability, etc. The downstream firm is likely to be free riding on the upstream firm. Based on above cases, this article is mainly to study how to carry out issues in cooperation to reduce carbon emissions of the supply chain.

For the study of convenience, this paper made the following assumptions as shown in Table 1 .

(1) Products belong to necessities and the market is an imperfect competitive one. Product demand is a linear function of the price.

(2) The inventory products between the two companies are zero.

(3) Carbon emissions per unit product are constant under the condition of a certain technology.

(4) The upstream enterprise knows the existing free riding opportunity of the downstream one, when the upstream enterprise makes investment to reduce emissions.

(5) Investment to reduce emissions cannot influence the production cost of the product.

(6) The emissions reduction rate is the monotone increasing function of investment to reduce emissions and the marginal reduction rate decreases with the increase of investment to reduce emissions.

(7) The carbon quota that the government allocates in a single cycle is an exogenous variable and cannot move to the next cycle.

(8) The downstream enterprise's cost change caused by the change of the production process and operation because of the upstream enterprise providing product changes in shape or property can be negligible.

(9) The carbon price is determined by the carbon trading market and is an exogenous variable.

Here are some simple equations in Table 1:

The equation of market demand and price is

$$
Q=N-b p \text {. }
$$

The equation of emissions reduction rate of carbon emissions reduction investment of the manufacturer $M_{1}$ is

$$
\frac{h_{M_{1}}-h_{M_{1}}^{\prime}}{h_{M_{1}}}=f(I)=2 m \sqrt{I}
$$

The equation of emissions reduction rate of carbon emissions reduction investment of the manufacturer $M_{2}$ is

$$
\frac{h_{M_{2}}-h_{M_{2}}^{\prime}}{h_{M_{2}}}=g(I)=2 n \sqrt{I}
$$

Obviously, consistent with the previous research and assumption (6), $f(I)$ and $g(I)$ satisfy.

$$
f^{\prime}(I)>0, f^{\prime \prime}(I)<0, g^{\prime}(I)>0, g^{\prime \prime}(I)<0,
$$

$f^{\prime}(I)>0$ and $g^{\prime}(I)>0$ indicate that emissions reduction rate is the increasing function of carbon emissions reduction investment. $f^{\prime \prime}(I)<0$ and $g^{\prime \prime}(I)<0$ indicate that emissions reduction rate is the convex function of carbon emissions reduction investment.

$\mathrm{NC}, \mathrm{C}$ and SNC respectively are denoted as decentralized decision making, centralized decision-making and 
Table 1

The Related Variables and Their Meanings

\begin{tabular}{|c|c|}
\hline Variables & Meanings \\
\hline$\overline{E_{M_{i}}}$ & Fixed carbon emissions of the manufacturer $M_{i}$, which has nothing to do with the product yield, $i=1,2$ \\
\hline$Q$ & Market demand \\
\hline$N$ & Capacity of the market \\
\hline$b$ & Demand price sensitive coefficient \\
\hline$c_{M_{i}}$ & The cost of production per unit product for the manufacturer $M_{i}, i=1,2$ \\
\hline$h_{M_{i}}$ & The initial carbon emissions of production per unit product for the manufacturer $M_{i}$ when they do not invest to reduce emissions, $i=1,2$ \\
\hline$h^{\prime}{ }_{M_{i}}$ & The carbon emissions of production per unit product for the manufacturer $M_{i}$, when they invest to reduce emissions, $i=1,2$ \\
\hline$p_{c}$ & The unit price of carbon dioxide \\
\hline$\omega$ & The wholesale price \\
\hline$p$ & The retail price \\
\hline$\pi_{M_{i}}$ & The profit of the manufacturer $M_{i}, i=1,2$ \\
\hline$I$ & Investment to reduce emissions of the manufacturer $M_{i}, i=1,2$ \\
\hline$\pi_{C}$ & The joint profit of the two manufacturers under centralized decision making \\
\hline$Z_{M_{i}}$ & Carbon quota that the government allocates to the manufacturer $M_{i}, i=1,2$ \\
\hline$m$ & The sensitive coefficient of emissions reduction rate of carbon emissions reduction investment of the manufacturer $M_{1}$ \\
\hline$n$ & The sensitive coefficient of emissions reduction rate of carbon emissions reduction investment of the manufacturer $M_{2}$ \\
\hline
\end{tabular}

decentralized decision making under the investment costsharing contract.

\section{Model analyses}

\subsection{The decentralized channel case}

Under decentralized decision-making, two manufacturers make decisions in order to maximize respective profit as the goal. It assumes that the manufacturer $M_{1}$ is the leader and the manufacturer $M_{2}$ is the follower. Therefore, manufacturer $M_{1}$ first determines the wholesale price and carbon emissions reduction investment, then, manufacturer $M_{2}$ decides the retail price according to the decision of manufacturer $M_{1}$.

The profit function of manufacturer $M_{1}$ is as follow.

$$
\begin{aligned}
\pi_{M_{1}}= & \left(\omega-c_{M_{1}}\right)(N-b p) \\
& -p_{c}\left[E_{M_{1}}+h_{M_{1}}^{\prime}(N-b p)-Z_{M_{1}}\right]-I
\end{aligned}
$$

The first part of the right side of the Eq. (4) shows the total earnings of manufacturer $M_{1}$ when it sells products to manufacturer $M_{2}$. The second part of the right side of the Eq. (4) denotes the earnings obtained by the carbon trading of manufacturer $M_{1}$. When $E_{M_{1}}+h_{M_{1}}^{\prime}(N-b p)<Z_{M_{1}}$, manufacturer $M_{1}$ will produce the carbon trading earnings. Otherwise, manufacturer $M_{1}$ will carry the carbon trading cost. The third part of the right side of the Eq. (4) demonstrates the carbon emissions reduction cost when manufacturer $M_{1}$ reduces carbon emissions.

The profit function of manufacturer $M_{2}$ is as follow.

$$
\begin{aligned}
\pi_{M_{2}}= & \left(p-\omega-c_{M_{2}}\right)(N-b p) \\
& -p_{c}\left[E_{M_{2}}+h_{M_{2}}^{\prime}(N-b p)-Z_{M_{2}}\right]
\end{aligned}
$$

The first part of the right side of the Eq. (5) shows the total earnings of manufacturer $M_{2}$ when it sells products to the upstream manufacturer. The second part of the right side of the Eq. (5) denotes the earnings obtained by the carbon trading of manufacturer $M_{2}$. When $E_{M_{2}}+h_{M_{2}}^{\prime}(N-b p)<Z_{M_{2}}$, manufacturer $M_{2}$ will produce the carbon trading earnings. Otherwise, manufacturer $M_{2}$ will carry the carbon trading cost.

Using the backward induction method to solve the model, first order $\partial \pi_{M_{2}} / \partial p=0$, get $p_{\mathrm{NC}}^{*}$. Then substitute $p_{\mathrm{NC}}^{*}$ into the Eq. (4) and command $\partial \pi_{M_{1}} / \partial \omega=0$, get

$$
\begin{gathered}
p_{\mathrm{NC}}^{*}=\frac{3 N+b\left(c_{M_{1}}+p_{c} h_{M_{1}}^{\prime}+c_{M_{2}}+p_{c} h_{M_{2}}^{\prime}\right)}{4 b} \\
\omega_{\mathrm{NC}}^{*}=\frac{N-b\left(c_{M_{2}}+p_{c} h_{M_{2}}^{\prime}-c_{M_{1}}-p_{c} h_{M_{1}}^{\prime}\right)}{2 b}
\end{gathered}
$$

Substitute $p_{\mathrm{NC}}^{*}$ and $\omega_{\mathrm{NC}}^{*}$ into Eq. (4), then obtain the derivative of $\pi_{M_{1}}$ to $I$. 


$$
\frac{\partial \pi_{M_{1}}}{\partial I}=\frac{2\left\{\left[N-b\left(c_{M_{1}}+p_{c} h_{M_{1}}+c_{M_{2}}+p_{c} h_{M_{2}}\right)\right]+2 b p_{c}\left(m h_{M_{1}}+n h_{M_{2}}\right) \sqrt{I}\right\} b p_{c}\left(m h_{M_{1}}+n h_{M_{2}}\right)}{8 b \sqrt{I}}-1
$$

The second derivative of $\pi_{M_{1}}$ to $I$ is

$$
\frac{\partial^{2} \pi_{M_{1}}}{\partial I^{2}}=\frac{p_{c}\left(m h_{M_{1}}+n h_{M_{2}}\right)\left[N-b\left(c_{M_{1}}+p_{c} h_{M_{1}}+c_{M_{2}}+p_{c} h_{M_{2}}\right)\right]}{8 \sqrt{I^{3}}}<0,
$$

so $\pi_{M_{1}}$ can get the maximal value when $\frac{\partial \pi_{M_{1}}}{\partial I}=0$. Therefore, order $\frac{\partial \pi_{M_{1}}}{\partial I}=0$, then obtain the optimal carbon

emissions reduction investment of manufacturer $M_{1}$ under decentralized decision making.

$$
\sqrt{I_{\mathrm{NC}}^{*}}=\frac{p_{c}\left(m h_{M_{1}}+n h_{M_{2}}\right)\left[N-b\left(c_{M_{1}}+p_{c} h_{M_{1}}+c_{M_{2}}+p_{c} h_{M_{2}}\right)\right]}{4-2 b p_{c}^{2}\left(m h_{M_{1}}+n h_{M_{2}}\right)^{2}}
$$

Theorem 1. (1) $I_{\mathrm{NC}}^{*}$ increases with the increase of $m$ and $n$. (2) $p_{\mathrm{NC}}^{*}$ decreases with the increase of $m$ and $n$. (3) $\omega_{\mathrm{NC}}^{*}$ decreases with the increase of $m$ and increases with the increase of $n$.

Proof. It is easy to prove by comparing the relationship of $I_{\mathrm{NC}}^{*}, p_{\mathrm{NC}}^{*}, \omega_{\mathrm{NC}}^{*}$ and $m, n$.

Theorem 1 shows that, the carbon emissions reduction investment of manufacturer $M_{1}$ increases with the increase of the sensitive coefficient of emissions reduction rate of carbon emissions reduction investment of manufacturer $M_{1}$ and manufacturer $M_{2}$. The higher the emissions reduction rates of the manufacturers are, the higher the carbon emissions reduction investment. However, slightly contrary to our expectation, the carbon emissions reduction investment of manufacturer $M_{1}$ increases with the increase of $n$ that can be used as measuring the degree of free riding of the downstream manufacturer. By observing the changing circumstance of $p_{\mathrm{NC}}^{*}$ and $\omega_{\mathrm{NC}}^{*}$ with the changing of $m$ and $n$, we can conclude that the wholesale price of manufacturer $M_{1}$ and the retail price of manufacturer $M_{2}$ increase with the increase of the sensitive coefficient of the emissions reduction rate of the carbon emissions reduction investment of manufacturer $M_{2}$ under the action of the price mechanism. That is to say, the situation existing in the price mechanism, although the downstream manufacturer is free riding on the carbon emissions reduction investment of the upstream manufacturer to reduce emissions, the upstream manufacturer will ignore the free riding behavior and make full use of this opportunity of carbon emissions reduction to decrease emissions.

The optimal profit of manufacturer $M_{1}$ and manufacturer $M_{2}$ and the total profit of the supply chain are as follows.

$$
\begin{aligned}
\pi_{M_{1}}^{\mathrm{NC}}= & \frac{\left[N-b\left(c_{M_{2}}+p_{c} h_{M_{2}}\left(1-2 n \sqrt{I_{\mathrm{NC}}^{*}}\right)+c_{M_{1}}+p_{c} h_{M_{1}}\left(1-2 m \sqrt{I_{\mathrm{NC}}^{*}}\right)\right]^{2}\right.}{8 b} \\
& -p_{c} E_{M_{1}}-I_{\mathrm{NC}}^{*}+p_{c} Z_{M_{1}} \\
\pi_{M_{2}}^{\mathrm{NC}^{*}=} & \frac{\left[N-b\left(c_{M_{2}}+p_{c} h_{M_{2}}\left(1-2 n \sqrt{I_{\mathrm{NC}}^{*}}\right)+c_{M_{1}}+p_{c} h_{M_{1}}\left(1-2 m \sqrt{I_{\mathrm{NC}}^{*}}\right)\right]^{2}\right.}{16 b} \\
& -p_{c} E_{M_{2}}+p_{c} Z_{M_{2}} \\
\pi_{\mathrm{NC}}^{*}= & \frac{3\left[N-b\left(c_{M_{2}}+p_{c} h_{M_{2}}\left(1-2 n \sqrt{I_{\mathrm{NC}}^{*}}\right)+c_{M_{1}}+p_{c} h_{M_{1}}\left(1-2 m \sqrt{I_{\mathrm{NC}}^{*}}\right)\right)\right]^{2}}{16 b} \\
& -p_{c}\left(E_{M_{1}}+E_{M_{2}}\right)-I_{\mathrm{NC}}^{*}+p_{c}\left(Z_{M_{1}}+Z_{M_{2}}\right)
\end{aligned}
$$




\subsection{The centralized channel case}

Under centralized decision-making, the manufacturers $M_{1}$ and $M_{2}$ will make a decision as a whole. They determine the product retail price and carbon emissions reduction investment with the goal of maximizing the profit of the whole supply chain.

The profit function of the whole supply chain is as follow.

$$
\begin{aligned}
\pi_{\mathrm{C}}= & \left(p-c_{M_{1}}-c_{M_{2}}\right)(N-b p) \\
& -p_{c}\left[E_{M_{1}}+h_{M_{1}}^{\prime}(N-b p)-Z_{M_{1}}\right] \\
& -I_{\mathrm{C}}-p_{c}\left[E_{M_{2}}+h_{M_{2}}^{\prime}(N-b p)-Z_{M_{2}}\right]
\end{aligned}
$$

The first part of the right side of the Eq. (12) shows the total earnings of the whole supply chain when it sells products to the downstream firm. The second part of the right side of the Eq. (12) denotes the earnings obtained by the carbon trading of manufacturer $M_{1}$. When $E_{M_{1}}+h_{M_{1}}^{\prime}(N-b p)<Z_{M_{1}}$, manufacturer $M_{1}$ will produce the carbon trading earnings. Otherwise, manufacturer $M_{1}$ will bring the carbon trading cost. The third part of the right side of the Eq. (12) demonstrates the carbon emissions reduction cost when manufacturer $M_{1}$ reduces carbon emissions. The fourth part of the right side of the Eq. (12) expresses the earnings obtained by the carbon trading of manufacturer $M_{2}$. When $E_{M_{2}}+h_{M_{2}}^{\prime}(N-b p)<Z_{M_{2}}$, manufacturer $M_{2}$ will produce the carbon trading earnings. Otherwise, the manufacturer $M_{2}$ will bring the carbon trading cost.

Thus equating the first order conditions to 0 and solving the equations simultaneously, we get

$$
\begin{aligned}
\frac{\partial \pi_{\mathrm{C}}}{\partial p} & =(N-b p)-b\left(p-c_{M_{1}}-p_{c} h_{M_{1}}^{\prime}-c_{M_{2}}-p_{c} h_{M_{2}}^{\prime}\right) \\
& =0 \\
\frac{\partial \pi_{C}}{\partial I} & =p_{c}(N-b p) \frac{1}{\sqrt{I}}\left(m h_{M_{1}}+n h_{M_{2}}\right)-1=0 \\
p_{\mathrm{C}}^{*} & =\frac{N+b\left(c_{M_{1}}+p_{c} h_{M_{1}}^{\prime}+c_{M_{2}}+p_{c} h_{M_{2}}^{\prime}\right)}{2 b}
\end{aligned}
$$$$
\sqrt{I_{\mathrm{C}}^{*}}=\frac{p_{c}\left(m h_{M_{1}}+n h_{M_{2}}\right)\left[N-b\left(c_{M_{1}}+p_{c} h_{M_{1}}+c_{M_{2}}+p_{c} h_{M_{2}}\right)\right]}{2-2 b p_{c}^{2}\left(m h_{M_{1}}+n h_{M_{2}}\right)^{2}}
$$

The Hessian $H_{c}$ is as follow.

$$
\begin{gathered}
H_{c}=\left[\begin{array}{ll}
-2 b & -b p_{c} \frac{1}{\sqrt{I}}\left(m h_{M_{1}}+n h_{M_{2}}\right) \\
-b p_{c} \frac{1}{\sqrt{I}}\left(m h_{M_{1}}+n h_{M_{2}}\right) & -\frac{p_{c}\left(m h_{M_{1}}+n h_{M_{2}}\right)(N-b p)}{2 I^{2}}
\end{array}\right] \\
\left|H_{c}\left(p_{\mathrm{C}}^{*}, I_{\mathrm{C}}^{*}\right)\right|=\frac{b\left[1-b p_{c}^{2}\left(m h_{M_{1}}+n h_{M_{2}}\right)^{2}\right]}{I_{\mathrm{C}}^{*}}>0
\end{gathered}
$$

Therefore, $\left(p_{\mathrm{C}}^{*}, I_{\mathrm{C}}^{*}\right)$ is the optimal solution of the profit function (12) of the whole supply chain.

Theorem 2. $I_{C}^{*}>I_{\mathrm{N} C}^{*}$.

The optimal carbon emissions reduction investment under centralized decision-making is greater than the one under decentralized decision making. This is due to the double marginal effect of the supply chain decisions. Therefore, although the price mechanism can weaken the free riding behavior of the supply chain, existing in the double marginal effect, the carbon emissions reduction investment of the supply chain under decentralized decision making still cannot achieve the optimal. Moreover, in accordance with the situation of decentralized decision-making situations and through the Eqs. (15) and (16), we get that the optimal retail price of the supply chain decreases and carbon emissions reduction investment increases with the increase of $m$ and $n$.

The optimal total profit of the supply chain is as follow.

$$
\begin{aligned}
\pi_{\mathrm{C}}^{*}= & \frac{\left[N-b\left(c_{M_{1}}+p_{c} h_{M_{2}}\left(1-2 n \sqrt{I^{*}}\right)+c_{M_{1}}+p_{c} h_{M_{1}}\left(1-2 m \sqrt{I_{\mathrm{C}}^{*}}\right)\right)\right]^{2}}{4 b} \\
& -p_{c}\left(E_{M_{1}}+E_{M_{2}}\right)-I_{\mathrm{C}}^{*}+p_{c}\left(Z_{M_{1}}+Z_{M_{2}}\right)
\end{aligned}
$$

Theorem 3. $\pi_{\mathrm{NC}}^{*}<\pi_{\mathrm{C}}^{*}$. 


\subsection{The investment cost sharing contract}

To encourage a better implementation of the supply chain to reduce emissions and reduce the influence of a double marginal effect on the supply chain, we designed an investment cost sharing contract to achieve supply chain coordination. It assumes that the carbon emissions reduction investment ratio that manufacturer $M_{2}$ undertakes is $\varphi(0<\varphi<1)$, so the carbon emissions reduction

investment ratio that manufacturer $M_{1}$ undertakes is $1-\varphi$. By solving the optimal decisions of manufacturers $M_{1}$ and $M_{2}$, we get

$$
\begin{array}{r}
p_{\mathrm{SNC}}^{*}=\frac{3 N+b\left(c_{M_{1}}+p_{c} h_{M_{1}}^{\prime}+c_{M_{2}}+p_{c} h_{M_{2}}^{\prime}\right)}{4 b} \\
\omega_{\mathrm{SNC}}^{*}=\frac{N-b\left(c_{M_{2}}+p_{c} h_{M_{2}}^{\prime}-c_{M_{1}}-p_{c} h_{M_{1}}^{\prime}\right)}{2 b}
\end{array}
$$

$$
\sqrt{I_{\mathrm{SNC}}^{*}}=\frac{p_{c}\left(m h_{M_{1}}+n h_{M_{2}}\right)\left[N-b\left(c_{M_{2}}+p_{c} h_{M_{2}}+c_{M_{1}}+p_{c} h_{M_{1}}\right)\right]}{4(1-\varphi)-2 b p_{c}^{2}\left(m h_{M_{1}}+n h_{M_{2}}\right)^{2}}
$$

By comparing the Eqs. (8) and (20), we get that the optimal carbon emissions reduction investment under the investment cost-sharing contract is always greater than the one without the investment cost-sharing contract. That is to say, the investment cost sharing contract can slow down the double marginal effect and improve the carbon emissions reduction investment of the supply chain.

Corollary $1 . I_{\mathrm{SNC}}^{*}>I_{\mathrm{NC}}^{*}, \pi_{\mathrm{SNC}}^{*}>\pi_{\mathrm{NC}}^{*}$.

Next step, we need determine the scope of $\varphi$ in order to make the profits of the manufacturers $M_{1}$ and $M_{2}$ under the investment cost sharing contract meet the participation constraint and incentive compatible constraint, that is $\pi_{M_{1}}^{\mathrm{SNC}^{*}}>\pi_{M_{1}}^{\mathrm{NC}}$ and $\pi_{M_{2}}^{\mathrm{NC}}>\pi_{M_{2}}^{\mathrm{NC}^{*}}$.

Theorem 4. When $0<\varphi<\min \left\{\frac{2-b x^{2}}{2}, \frac{2-b x^{2}}{4 b^{-1} x^{-2}-1}\right\}$, $x=p_{c}\left(m h_{M_{1}}+n h_{M_{2}}\right)$, the supply chain can realize the Pareto improvement.

Proof. By solving in equality group $\pi_{M_{1}}^{\mathrm{SNC}^{*}}>\pi_{M_{1}}^{\mathrm{NC}}$ and $\pi_{M_{2}}^{\mathrm{SNC} *}>\pi_{M_{2}}^{\mathrm{NC}}$, we can get Corollary 2. $\varphi<1 / 2$ always holds.

Corollary 2 indicates that the investment cost sharing contract can improve the optimal carbon emissions reduction investment of the manufacturer (greater than the optimal carbon emissions reduction investment under the decentralized decision making) but still cannot reach the optimal emissions reduction level under centralized decision making.

Theorem 5. When $\varphi^{*}=1-\frac{t+\sqrt{(t-1)(t-3)}}{2}$, $t=b p_{c}^{2}\left(m h_{M_{1}}+n h_{M_{2}}\right)^{2}$, the total profit of the supply chain under the investment cost sharing contract and centralized decision making is equal, among $1-\sqrt{3} / 2<\varphi<1 / 2$. What is more, the higher the unit price of carbon dioxide is, the higher the carbon emissions reduction investment ratio that the downstream manufacturer undertakes.

Due to $\varphi^{*}$ satisfying theorem 5 is still smaller than $1 / 2$, the investment cost sharing contract may achieve the supply chain coordination. By comparing the scope of $\varphi^{*}$ with $\varphi$ meeting participation constraint, we get Corollary 3 . $\exists 0<t_{1}<t_{2}<1$, when $t \in\left(0, t_{1}\right)$ or $t \in\left(t_{2}, 1\right)$, the investment cost sharing contract may achieve the supply chain coordination. Otherwise, the investment cost sharing contract cannot achieve the supply chain coordination.

Corollary 3 indicates that the investment cost sharing contract may not achieve the supply chain coordination in all cases. When $b p_{c}^{2}\left(m h_{M_{1}}+n h_{M_{2}}\right)^{2}$ is smaller or larger, the investment cost sharing contract cannot achieve the supply chain coordination.

\section{Model extensions}

The fourth part of analysis in this paper indicates that when the upstream manufacturer masters pricing power, it can transfer part of the carbon emissions reduction investment cost by the price mechanism and slow down the free riding behavior of the downstream manufacturer. However, in reality, in the short-term or when prices are rigid, the investment cost of the upstream manufacturer not necessarily can influence the price, thus affecting the product yield and income. Therefore, in this part we consider the optimal decisions of the upstream and downstream manufacturers when the carbon emissions reduction investment cannot influence the product price and income.

First the profit functions of manufacturer $M_{1}$ and $M_{2}$ without carbon emissions reduction investment are as follows.

$$
\pi_{M_{1}}=\left(\omega-c_{M_{1}}\right)(N-b p)-p_{c}\left[E_{M_{1}}+h_{M_{1}}(N-b p)-Z_{M_{1}}\right]
$$

$\pi_{M_{2}}=\left(p-\omega-c_{M_{2}}\right)(N-b p)-p_{c}\left[E_{M_{2}}+h_{M_{2}}(N-b p)-Z_{M_{2}}\right]$

By solving the model, we get the wholesale price and retail price.

$$
\omega^{*}=\frac{N-b\left(c_{M_{2}}+p_{c} h_{M_{2}}-c_{M_{1}}-p_{c} h_{M_{1}}\right)}{2 b}
$$




$$
p^{*}=\frac{3 N+b\left(c_{M_{1}}+p_{c} h_{M_{1}}+c_{M_{2}}+p_{c} h_{M_{2}}\right)}{4 b}
$$

Then, the upstream manufacturer $M_{1}$ determines to introduce carbon emissions reduction investment $I$ to reduce its carbon emissions, but this investment does not affect the product yield and price. By solving the profit function (25) of manufacturer $M_{1}$ after carbon emissions reduction,

$$
\begin{aligned}
\pi_{M_{1}}= & \left(\omega^{*}-c_{M_{1}}\right)\left(N-b p^{*}\right) \\
& -p_{c}\left[E_{M_{1}}+h_{M_{1}}^{\prime}\left(N-b p^{*}\right)-Z_{M_{1}}\right]-I
\end{aligned}
$$

We get

$$
\begin{aligned}
\sqrt{I^{*}} & =m h_{M_{1}} p_{c}\left(N-b p^{*}\right) \\
& =\frac{m h_{M_{1}} p_{c}\left[N-b\left(c_{M_{1}}+p_{c} h_{M_{1}}+c_{M_{2}}+p_{c} h_{M_{2}}\right)\right]}{4}
\end{aligned}
$$

By comparing Eq. (26) with Eq.(8), we know that the optimal investment when the carbon emissions reduction investment of the upstream manufacturer does not affect the product price is smaller than the optimal investment when the carbon emissions reduction investment of the upstream manufacturer affects the product price. Obviously, when the upstream manufacturer cannot transfer part of the carbon emissions reduction investment to the downstream manufacturer by the product price, its own carbon emissions reduction investment will decrease.

This moment the economic costs due to the carbon emissions reduction investment of the upstream and downstream firms are as follows.

$$
\begin{aligned}
p_{c}\left(h_{M_{1}}-h_{M_{1}}^{\prime}\right)\left(N-b p^{*}\right)-I^{*} & =\left[m h_{M_{1}} p_{c}\left(N-b p^{*}\right)\right]^{2}=I^{*} \\
p_{c}\left(h_{M_{2}}-h_{M_{2}}^{\prime}\right)\left(N-b p^{*}\right) & =2 m h_{M_{1}} n h_{M_{2}} p_{c}^{2}\left(N-b p^{*}\right)^{2} \\
& =\frac{2 n h_{M_{2}}}{m h_{M_{1}}} I^{*}
\end{aligned}
$$

According to Eq. (28), the earnings caused by the free riding behavior of the downstream manufacturer increase with the increase of the initial carbon emissions of the upstream and downstream manufacturers and the sensitive coefficient of the emissions reduction rate of carbon emissions reduction investment $m$ and $n$. But its proportion accounting for carbon emissions reduction investment decreases with the increase of the initial carbon emissions of the upstream manufacturer and the sensitive coefficient of the emissions reduction rate of carbon emissions reduction investment $m$.

If the upstream and downstream firms focus determines the carbon emissions reduction investment, the optimal investment of manufacturer $M_{1}$ is as follow.

$$
\begin{aligned}
\sqrt{I_{\mathrm{C}}^{*}} & =p_{c}\left(m h_{M_{1}}+n h_{M_{2}}\right)\left(N-b p^{*}\right) \\
& =\frac{p_{c}\left(m h_{M_{1}}+n h_{M_{2}}\right)\left[N-b\left(c_{M_{1}}+p_{c} h_{M_{1}}+c_{M_{2}}+p_{c} h_{M_{2}}\right)\right]}{4}
\end{aligned}
$$

This moment the economic costs due to the carbon emissions reduction investment of the upstream and downstream firm are as follows.

$$
\begin{aligned}
& p_{c}\left(h_{M_{1}}-h_{M_{1}}^{\prime}\right)\left(N-b p^{*}\right)-I_{\mathrm{C}}^{*} \\
&=\left(m^{2} h_{M_{1}}^{2}-n^{2} h_{M_{2}}^{2}\right) p_{c}^{2}\left(N-b p^{*}\right)^{2} \\
&= \frac{m^{2} h_{M_{1}}^{2}-n^{2} h_{M_{2}}^{2}}{m h_{M_{1}}+n h_{M_{2}}} I_{\mathrm{C}}^{*} \\
& p_{c}\left(h_{M_{2}}-h_{M_{2}}^{\prime}\right)\left(N-b p^{*}\right) \\
&=2 n h_{M_{2}}\left(m h_{M_{1}}+n h_{M_{2}}\right) p_{c}^{2}\left(N-b p^{*}\right)^{2} \\
&=\frac{2 n h_{M_{2}}}{m h_{M_{1}}+n h_{M_{2}}} I_{\mathrm{C}}^{*}
\end{aligned}
$$

By comparing the carbon emissions reduction earnings of the upstream and downstream manufacturers when the upstream manufacturer alone makes decisions with the earnings when the upstream and downstream manufacturers mutually make decisions, we can obtain that when the upstream and downstream manufacturers determine the carbon emissions reduction investment, the supply chain may reduce more carbon emissions. However, the upstream manufacturer will also carry more investment costs from this, resulting in the earnings of the upstream manufacturer decreasing but the downstream manufacturer getting more free riding earnings. Therefore, the upstream and downstream manufacturers can establish a cost-sharing mechanism to encourage the upstream manufacturer to invest to reduce emissions based on the goal that maximizes the profit of the whole supply chain. The scope of the proportion of the carbon emissions reduction investment that the downstream manufacturer undertakes is as shown in Theorem 6.

Theorem 6.

$$
\left(\frac{n h_{M_{2}}}{m h_{M_{1}}+n h_{M_{2}}}\right)^{2}<\varphi<2\left(\frac{n h_{M_{2}}}{m h_{M_{1}}+n h_{M_{2}}}\right)^{2}
$$

Theorem 6 indicates that the larger the degree of free riding of the downstream manufacturer is, the larger the proportion of the carbon emissions reduction investment that the downstream manufacturer undertakes is to relieve the impact of free riding behavior to the whole supply chain efficiency. 


\section{Conclusions}

This study investigates the impact of free riding on enterprise product pricing and carbon emissions reduction investment, as well as the contract design to achieve supply chain coordination under the carbon trading mechanism. The main conclusions are as follows.

When the product yield and price can be adjusted with the carbon emissions reduction investment, the optimal carbon emissions reduction investment of the upstream manufacturer not only increases with the increase of the sensitive coefficient of the emissions reduction rate of carbon emissions reduction investment of itself, but also rises with the increase of the degree of free riding of the downstream manufacturer. It indicates that in this situation the upstream manufacturer will ignore the free riding behavior and make full use of this opportunity of carbon emissions reduction to reduce emissions.

Due to the existence of the double marginal effect, the optimal carbon emissions reduction investment under centralized decision-making is greater than the one under decentralized decision making. Under the investment costsharing contract, we get that the optimal carbon emissions reduction investment is always greater than the one without the investment cost-sharing contract and this realizes the Pareto improvement. However, the investment cost sharing contract cannot make the optimal carbon emissions reduction investment reach the optimal emissions reduction level under centralized decision making. Only in certain situations is the total profit of the supply chain under the investment cost sharing contract and centralized decisionmaking equal. Therefore, the investment cost sharing contract can only partly coordinate the supply chain.

When the product yield and price cannot be adjusted with the carbon emissions reduction investment, the optimal carbon emissions reduction investment of the upstream manufacturer only relates with its own sensitive coefficient of the emissions reduction rate of the carbon emissions reduction investment. Compared with the situation of adjusting, its own carbon emissions reduction investment will decrease. The earnings caused by the free riding behavior of the downstream manufacturer increase with the rise of the initial carbon emissions of the upstream and downstream manufacturers and the sensitive coefficient of the emissions reduction rate of carbon emissions reduction investment, but its proportion accounting for carbon emissions reduction investment decreases with the increase of the initial carbon emissions and the sensitive coefficient of the emissions reduction rate of the carbon emissions reduction investment of the upstream manufacturer. When the upstream and downstream manufacturers focus to determine the carbon emissions reduction investment, the supply chain may achieve to reduce more carbon emissions; however, the upstream manufacturer will also have more investment cost from this resulting in the earnings of the upstream manufacturer decreasing but the downstream manufacturer getting more free riding earnings. Therefore, the upstream and downstream manufacturers can establish a cost-sharing mechanism to encourage the upstream manufacturer to invest to reduce emissions. This based on the goal to maximize the profit of the whole supply chain. Then, the proportion of the cost undertaken by the downstream manufacturer rises with the increase of the degree of its free riding.

This research can provide a reference for solving the problem of free riding existing in firms in a supply chain investing to reduce emissions. It is good for improving the level of the enterprise's carbon emissions reduction and supply chain efficiency, but this paper has some limits. First, it assumes that the upstream manufacturer is aware of free riding behavior of the downstream manufacturer, but in fact due to existing in an information asymmetry, the downstream manufacturer is likely to conceal the information of its free riding to obtain more earnings. Furthermore, other ways of coordination and the behavior of the consumer preferences are not considered. The above situations will be further researched in the future.

Acknowledgements The authors thank the reviewers and the editors for their detailed comments and many valuable suggestions that have significantly improved the quality of this paper. This research was supported by the Postdoctoral Science Foundation of China (2014M562145), the Key Projects of the National Natural Science Foundation of China (71431006), and the Education Ministry Social Science of China (13JZD016).

\section{References}

Ai, X., Ma, J., Chen, Z., \& Tang, X. (2011). Coordination mechanism of e-channel and traditional channel under service free-riding. Journal of Systems Engineering, 26, 507-514

Benjaafar, S., Li, Y., \& Daskin, M. (2010). The Carbon Footprint of UHT Milk. Minneapolis: University of Minnesota Press

Benjaafar, S., Li, Y., \& Daskin, M. (2013). Carbon footprint and the management of supply chains: Insights from simple models. IEEE Transactions on Automation Science and Engineering, 10, 99-116

Cachon, G.P. (2014). Retail store density and the cost of greenhouse gas emissions. Management Science, 60, 1907-1925

Carlton, D.W., \& Chevalier, J.A. (2001). Free riding and sales strategies for the Internet. Journal of Industrial Economics, 49, 441-461

Caro, F., Corbett, C.J., Tan, T., \& Zuidwijk, R.A. (2013). Double counting in supply chain carbon footprinting. Manufacturing \& Service Operations Management: $M$ \& SOM, 15, 545-558

Chaabane, A., Ramudhin, A., \& Paquet, M. (2012). Design of sustainable supply chains under the emission trading scheme. International Journal of Production Economics, 135, 37-49

Ding, Z., \& Liu, Y. (2013). Revenue sharing contract in dual channel supply chain in case of free riding. Journal of Systems Engineering, 28, 370-376

Du, S., Dong, J., Liang, L., \& Zhang, J. (2009). Optimal production policy with emission permits and trading. Chinese Journal of 
Management Science, 17, 81-86

Du, S., Ma, F., Fu, Z., Zhu, L., \& Zhang, J. (2015). Game-theoretic analysis for an emission-dependent supply chain in a 'cap-and-trade' system. Annals of Operations Research, 228, 135-149

He, D., \& Ma, H. (2011). Strategy of enterprise production and store under constraints of carbon emission. Resources \& Industries, 13, 63 68

Hua, G., Cheng, T., \& Wang, S. (2011). Managing carbon footprints in inventory management. International Journal of Production Economics, 132, 178-185

Koomen, A. (2012). Evaluating the impact of system boundaries on decisions that affect $\mathrm{CO}_{2}$ emissions and costs (unpublished Master's thesis). Eindhoven University of Technology, Eindhoven, The Netherlands

Li, Y., \& Zhao, D. (2014). Low-carbonization supply chain two-part tariff coordination based on fairness preference. Management Review, 26, 159-167

Li, Y., \& Zhao, D. (2015). Low-carbonization supply chain coordination with contracts considering fairness preference. Journal of Industrial Engineering and Engineering Management, 29, 156-161

Ma, Q., Song, H., \& Chen, G. (2014). A study on low-carbon product pricing and carbon emission problems under the cap-and-trade system. Journal of Industrial Engineering and Engineering Management, 28, 127-136

Nayak, G., \& Kumar, V. (2006). Jotun paints-product life cycle assessment. Retrieved from http://www.thefuturebuild.com/productlife-cycle-assessment-981475/file-files/DC8_JotunPaints_Product-
CarbonFootprint_FINAL_for \%20Masdar.pdf

Shi, Z., \& Zhao, D. (2013). Research on cooperation alliance of carbon emission reduction in the supply chain based on voluntary market. Journal of Northwestern Polytechnical University [Social Sciences], 33, 41-47

Wang, Q.P., \& Zhao, D.Z. (2014). Cooperative strategy of carbon emissions reduction and promotion in a two-echelon supply chain. Control and Decision, 29, 307-314

Xia, L., Zhao, D., He, L., \& Li, Y. (2014). Game on carbon emission reduction and coordination based on side-payment self-enforcing contract between supplier and manufacturer. Chinese Journal of Management, 11, 750-757

Xie, X., \& Zhao, D. (2013). Research on cooperation strategy of enterprises' carbon emission reduction in low carbon supply chain. Journal of Management Science, 26, 108-119

Xing, D., \& Liu, T. (2012). Sales effort free riding and coordination with price match and channel rebate. European Journal of Operational Research, 219, 264-271

Xu, B., \& Liu, L. (2014). A study of the order and information free-riding behavior of dual-channel supply chain based on CVaR criterion. Industrial Engineering Journal, 17, 99-107

Xu, C., Zhao, D., \& Yuan, B. (2015). Study on coordination mechanisms and differential pricing of supply chain in low carbon environment. Operations Research and Management Science, 24, 19-26

Zhang, J., Nie, T., \& Du, S. (2011). Optimal emission-dependent production policy with stochastic demand. International Journal of Society Systems Science, 3, 21-39 